\title{
Competenties van verpleegkundigen in het ethisch overleg in verpleeghuizen
}

\author{
B. Cusveller, H. Huijser, D. Klinkhamer-Hazeleger, J. Zwart-van Dommelen
}

\begin{abstract}
Samenvatting
Inleiding: Verpleegkundigen krijgen in de praktijk met ethische onderwerpen te maken, ook in de verpleeghuissector. Het verpleegkundige competentieprofiel stelt dat ze in staat zijn te participeren in ethische commissies. Wat dat inhoudt is niet duidelijk en hoe deze competenties onderwezen moet worden evenmin. Aangezien in de verpleeghuissector weinig verpleegkundigen met ethische commissies te maken krijgen is de vraag: welke competenties hebben verpleegkundigen nodig om te kunnen participeren in georganiseerde vormen van ethisch overleg (al dan niet in ethische commissies) in verpleeghuizen?
\end{abstract}

Methode: Om een antwoord te krijgen op deze vraag zijn in willekeurig gekozen verpleeghuizen interviews gehouden met elf verpleegkundigen die deelnemen aan een vorm van georganiseerd ethisch overleg. De vragen zijn gericht op de inhoud van de beroepscompetenties, namelijk kennis, houding en vaardigheden. Daarnaast zijn vragen gesteld aangaande het ethisch overleg, ethische onderwerpen en het ethiekonderwijs.

Resultaten: De resultaten zijn weergegeven in het format van een verpleegkundig competentieprofiel, met aanbevelingen aan de opleidingen. Vooral kennis van de organisatie en van wet- en regelgeving, een empathische en respectvolle houding en de vaardigheden luisteren en argumenteren zijn belangrijk. Door alle respondenten worden dilemma's rond dood en sterven ervaren, en dan vaak rond vocht en voeding.

Conclusies: Verpleegkundigen met werkervaring zijn in staat deel te nemen aan ethisch overleg in de verpleeghuissector. Wel missen ze kennis van wet- en regelgeving. Door dichter bij de praktijk te blijven zou het ethiekonderwijs in de verpleegkunde hier meer aandacht aan kunnen besteden. De bevindingen zijn generiek en van belang voor andere gezondheidszorgprofessionals. (Cusveller B, Huijser H, Klinkhamer-Hazeleger D, Zwart-van Dommelen J. Competenties van verpleegkundigen in het ethisch overleg in verpleeghuizen. Tijdschrift voor Medisch Onderwijs 2011;30(1-2):11-21)

\section{Inleiding}

De gezondheidszorg van vandaag confronteert zorgverleners met ethische onderwerpen. ${ }^{1}$ Ethiekonderwijs in de verschillende beroepsopleidingen tot professional in de gezondheidszorg is dan ook van belang. Het ministerie van VWS heeft laten onderzoeken of het ethiekonderwijs in gezondheidszorgopleidingen voldoet. ${ }^{2-3}$ De resultaten wijzen uit dat de opzet van het ethiekonderwijs in de zorg varieert; de onderzoekers vragen zich ook af of onder- wijs en praktijk voldoende op elkaar aansluiten en ze zijn van mening dat er meer samenwerking zou moeten zijn rond het ethiekonderwijs in gezondheidszorgopleidingen. Nader onderzoek naar de effectiviteit van ethiekbeoefening en ethiekonderwijs in de gezondheidszorg wordt dan ook aanbevolen.

Er zijn academische centra in Nederland waar dit onderzoek plaatsvindt; de invoering van een 'moreel beraad', als methode voor ethisch overleg in zorginstel- 
lingen, is daarvan een uitvloeisel. ${ }^{4}$ Het moreel beraad is een multidisciplinaire vorm van overleg waarbij in een vaste werkvorm met een vaste gespreksleider wordt ingegaan op de ethische onderwerpen in de zorg van alledag. Dit artikel spitst zich toe op deze ontwikkeling, met name op de verpleegkundige beroepsgroep en op het onderwijs aan deze beroepsgroep.

In de uitgave 'Beroepsprofiel van de verpleegkundige' wordt gesteld dat “...de verpleegkundige kan [...] omgaan met ethische kwesties. Zij maakt daarbij gebruik van een verpleegkundige beroepscode, de regels vanuit de organisatie en de wetgeving”. ${ }^{5}$ Conform het 'Besluit Opleidingseisen Verpleegkunde' wordt verlangd dat beroepsethiek onderdeel is van het onderwijsprogramma van de opleiding tot verpleegkundige. In het boek 'Met het oog op de toekomst' zijn de eindtermen van het verpleegkundig beroepsonderwijs uitgewerkt in twaalf verpleegkundige kerncompetenties, ondergebracht in vijf beroepsrollen. ${ }^{6}$ Dit competentieprofiel is inmiddels in het hogere beroepsonderwijs in de verpleegkunde (HBO-V) algemeen aanvaard.

Onder de competentie 'vernieuwen van het beroep en bevorderen van het beroepsbewustzijn' wordt gesteld: “Bij [de competentie] beroepsinnovatie door de hbo-verpleegkundige gaat het om [...] participeren in ethische commissies". De hoofdauteur van het hier bovengenoemde competentieprofiel geeft aan (persoonlijke communicatie, 23 juni 2008) dat verpleegkundigen die deze vaardigheid beheersen ook aan andere vormen van ethisch overleg kunnen deelnemen. Het is de vraag of voor onderwijsdoeleinden deze deelcompetentie 'participeren in ethische commissies' voldoende duidelijk is. Eerdere verkenningen gaven informatie over de kennis, houding en vaardigheden die verpleegkundigen moeten verwerven om competent te zijn in overlegvormen over ethische onderwerpen in de sectoren algemene gezondheidszorg (AGZ), geestelijke gezondheidszorg (GGZ), maatschappelijke gezondheidszorg (MGZ) en verstandelijk gehandicaptenzorg (VGZ). ${ }^{7-10}$ Ter aanvulling en vergelijking gaat dit artikel in op de competenties van verpleegkundigen aangaande deelname aan overlegvormen over ethische onderwerpen in de verpleeghuissector.

Uit onderzoek blijkt dat ook in de verpleeghuiszorg de zorgverleners op ethische onderwerpen stuiten. Van Dartel et al. wijzen op het weigeren van eten en drinken door zorgvragers, het fixeren van zorgvragers bij onrust, het meewerken bij levensbeëindigend handelen, de privacy en intimiteit van zorgvragers, en de bejegening, autonomie, culturele diversiteit, enz. ${ }^{11}$ Van Thiel en Van den Hove deden onderzoek naar ethische knelpunten in de care-sector (verpleeghuizen, instellingen voor mensen met een verstandelijke beperking, thuiszorg). ${ }^{12}$ Ze rangschikten hun uitkomsten in drie categorieën: 1) zorg op maat versus de wens van de zorgvrager en de beschikbaarheid van middelen, 2) normalisatie en autonomie van de zorgvrager versus de professionele verantwoordelijkheid van de zorgverlener, en 3) professionaliteit versus betrokkenheid, dat wil zeggen het evenwicht tussen vaste vormen voor zorg en de gewenste uitkomsten van zorg.

In de ouderenzorg en in de verpleeghuissector is moreel beraad in opkomst. ${ }^{13-14}$ Scholing van gezondheidszorgprofessionals is hier van belang. De toespitsing op de rol van de verpleegkundige hierin en de hieraan inherente gewenste competenties ethische onderwerpen ter sprake te brengen, en wat dat inhoudt, vraagt om nader onderzoek. 


\section{Probleemstelling}

Met het oog op het versterken van het verpleegkundige beroepsonderwijs en -beroepsveld is het doel de strekking van de competentie 'participeren in ethische commissies', in het bijzonder in de verpleeghuissector, te verhelderen. Er zijn aanwijzingen dat in de verpleeghuissector (300-400 instellingen) minder ethische commissies actief zijn dan in andere sectoren. Van Dartel et al. geven aan dat 38\% van de instellingen in de GGZ en 35\% van de instellingen in de ouderenzorg een actieve ethische commissie kennen. Daarnaast werken er in verpleeghuizen verhoudingsgewijs minder verpleegkundigen dan in andere sectoren. Van de 149.000 werkzame verpleegkundigen in 2009 werkten er 2.100 met een HBO- en 21.300 met een MBO-diploma in verpleeg- en verzorgingshuizen. ${ }^{15}$ Het is dus denkbaar dat zelfs in het geval dat er een ethische commissie is, er weinig of geen verpleegkundigen in participeren. Om die reden richten de vragen van deze verkenning zich ook op verpleegkundigen in verpleeghuizen die in andere formele of georganiseerde verbanden structureel overleg voeren over ethische onderwerpen, zoals interdisciplinair overleg, moreel beraad of commissievergaderingen (klachtencommissies of cliëntenraden).

De hoofdvraag is: welke competenties hebben verpleegkundigen nodig om te kunnen participeren in (georganiseerd) ethisch overleg in verpleeghuizen? Als eerste verkenning is de vraag geoperationaliseerd als: welke competenties worden door verpleegkundigen die in verpleeghuizen werken als noodzakelijk aangemerkt om competent te kunnen deelnemen aan ethisch overleg? Het doel is aan de hand van de verkregen gegevens aanbevelingen te kunnen doen voor het ethiekonderwijs in de gezondheidszorgopleidingen.

\section{Begripsverheldering}

In de gezondheidszorg worden twee soorten ethische commissies onderscheiden. ${ }^{16}$ In dit artikel wordt niet gedoeld op medisch-ethische toetsingscommissies. Deze zijn wettelijk verplicht voor instellingen waar wetenschappelijk onderzoek wordt verricht; zij zien er bijvoorbeeld op toe of belangen van de zorgvragers zijn beschermd.

In deze verkenning gaat het om zorggerelateerde ethische commissies, dat wil zeggen ethische commissies met een brede taakstelling. Het begrip 'competentie' is in het beroepsonderwijs in zwang voor een geïntegreerd cluster van kennis, houdingen en vaardigheden dat nodig is voor het oplossen van een centraal beroepsprobleem of voor het leveren van een centraal beroepsproduct. ${ }^{17}$ Een voorbeeld uit de verpleeghuissector is de dagelijkse zorg voor de hygiëne van een verwarde patiënt.

\section{Methode}

Opzet

Voor een verkenning van de ervaringen en inzichten van respondenten is een kwalitatief onderzoek geschikt. Aan drie studenten van een hogere verpleegkundige beroepsopleiding is de bovengenoemde hoofdvraag als afstudeeronderwerp gegeven. Voor dit praktijkonderzoek werd op basis van een literatuurstudie (en met name de eerdergenoemde onderzoeken naar competenties voor participatie in ethische commissies) een vragenlijst ontwikkeld. Dit is niet alleen van belang met het oog op intersubjectiviteit, maar maakte ook een vergelijking met en een aanvulling op eerder genoemde onderzoeken mogelijk.

De feedback aangaande betrouwbaarheid van de vragenlijsten uit deze eerdergenoemde onderzoeken, waarin topics over de componenten van een competen- 


\section{Box 1. Interviewschema}

\section{Intro}

In het interview willen wij ons vooral richten op de rol van de verpleegkundige in het moreel beraad. Onder moreel beraad verstaan wij het kritisch nadenken over wat onder goede zorg wordt verstaan en het bevorderen van reflectie op de zorg die geleverd wordt. In dit interview vragen wij vooral door op de manier waarop de verpleegkundige vorm geeft aan het gesprek over ethische onderwerpen. Welke kennis, houding en vaardigheden vinden verpleegkundigen dat zij nodig hebben bij ethisch overleg/moreel beraad? Wij willen te weten komen welke kwaliteiten verpleegkundigen in huis moeten hebben om mee te doen aan dit gesprek.

\section{Ethische commissie en moreel beraad}

1. Welke onderwerpen worden er zoal besproken in het ethisch overleg?

2. Welke taak heeft de ethische commissie in de instelling? Hoe is de ethische commissie gezien haar taak ingebed in de organisatie?

\section{Houding}

3. Wat bewoog $\mathrm{u}$ om deel te gaan nemen aan een ethische commissie/ethisch overleg?

4. Welke professionele houding heeft $\mathrm{u}$ nodig / gebruikt $\mathrm{u}$ om naar behoren deel te nemen aan ethisch overleg?

5. Welke eigenschappen vanuit uw persoon, karakter komen u goed van pas bij het voeren van ethisch overleg?

\section{Kennis}

6. Welke kennis of ervaring moeten verpleegkundigen volgens $\mathrm{u}$ in huis hebben om deel te nemen aan ethisch overleg?

7. Waar heeft u deze kennis opgedaan?

8. Heeft u wel eens kennistekort ervaren met betrekking tot ethiek tijdens ethisch overleg?

\section{Vaardigheden}

9. Welke vaardigheden heeft $\mathrm{u}$ nodig om ethisch overleg te kunnen voeren?

10. Tegen welke knelpunten loopt $u$ aan in ethisch overleg?

11. Waarom is het volgens $u$ belangrijk dat juist een verpleegkundige deelneemt aan ethisch overleg / in de ethische commissie?

\section{Ethiek in de opleiding}

12. In hoeverre zijn pas afgestudeerde verpleegkundigen in staat om te participeren in ethisch overleg of in een ethische commissie, denkt $u$ ?

13. Wat moet de opleiding aanbieden om studenten verpleegkunde toe te rusten voor deelname aan ethisch overleg of deelname aan een ethische commissie?

\section{Algemeen}

14. Welke opleiding heeft u gevolgd?

15. In welk jaar bent u gediplomeerd tot verpleegkundige?

16. Hoe lang bent u werkzaam binnen de verpleeghuissector?

17. Hoe lang participeert $u$ in de ethische commissie? 
tie (kennis, houding en vaardigheden), met daarnaast vragen over onderwerpen en randvoorwaarden, werd toegepast bij het ontwikkelen van de nieuwe vragenlijst.

Er is gestart met een pilotinterview met een verpleegkundige die deelneemt aan het ethisch overleg in een verpleeghuis; de volgende items kwamen hierin aan bod:

- De aard van het ethisch overleg, moreel beraad en ethische commissie

- Professionele houding en persoonlijke eigenschappen

- Kennis die nodig is voor deelname aan ethisch overleg

- Vaardigheden die nodig zijn voor deelname aan ethisch overleg

- Ethiek in de opleiding

- Algemene gegevens

$\mathrm{Na}$ het afnemen van de pilot werd geconcludeerd dat de topics in het interviewschema (zie Box 1) relevant en geschikt waren om antwoord te krijgen op de onderzoeksvraag; er werden geen wijzigingen in het schema aangebracht. Verder leverde het interview geen informatie op buiten de onderwerpen van de topiclijst. De uitkomsten van het pilotinterview zijn meegenomen in de resultaten van het onderzoek.

\section{Respondenten}

De populatie bestond uit verpleegkundigen die participeren in ethische commissies of in andere vormen van (georganiseerd) ethisch overleg binnen de verpleeghuissector. Om met respondenten in contact te komen werd aselect een aantal verpleeghuizen gekozen uit de woonomgeving van de onderzoekers. Er is geen inclusie of exclusie van bepaalde kenmerken van de verpleegkundigen of van de instellingen waar zij werken. Het gaat om een beperkte steekproef van verpleeghuizen in het midden van het land.
Aan de benaderde instellingen werd gevraagd of er een ethische commissie actief is en of er verpleegkundigen in participeren. Snel werd duidelijk dat in zes van deze verpleeghuizen geen ethische commissie aanwezig is; was er wel sprake van een ethische commissies dan was deze óf niet altijd actief, óf er participeerden niet altijd verpleegkundigen in. Van de benaderde instellingen hebben slechts twee verpleeghuizen een functionerende ethische commissie met daarin een verpleegkundige. In twee andere verpleeghuizen wordt, als dat nodig is, een commissie bijeen geroepen; in één verpleeghuis was er sprake van een 'slapende' ethische commissie. Drie verpleeghuizen waren bezig met het starten van een ethische commissie.

Voor kwalitatief onderzoek van dit type zijn ongeveer tien respondenten nodig. Aanvankelijk was het plan om respondenten te selecteren die op dat moment deelnamen aan een ethische commissie. Zoals gezegd bleek dat niet haalbaar, omdat het grootste deel van de verpleeghuizen geen ethische commissie heeft. Daarom is ervoor gekozen uit de benaderde verpleeghuizen respondenten te selecteren die ervaring hebben met een of andere vorm van ethisch overleg. Er werden uiteindelijk 11 respondenten geïnterviewd. In het laatste interview werd geen nieuwe informatie gevonden. Daarmee werd verzadiging bereikt en was de steekproef groot genoeg om algemene uitspraken te doen.

\section{Analyse}

De studenten namen in tweetallen de interviews af; deze werden op band opgenomen, en woordelijk op schrift uitgewerkt. Relevante tekst uit deze verbatimverslagen werd na fragmenteren ondergebracht in kernlabels. Er is gebruik gemaakt van de door Baarda et al. beschreven analysemethode voor kwalitatieve gegevens uit 
interviews, waarin de onderzoeksgegevens in zeven stappen verwerkt worden: ${ }^{18}$

1. Het labelen

2. Labels ruimtelijk ordenen en er verbanden tussen vinden

3. Het interpreteren en benoemen van de labelstructuur

4. Het vaststellen van de geldigheid van de labels

5. Het definiëren van de kernlabels

6. Het vaststellen van de intersubjectiviteit

7. Het beantwoorden van de probleemstelling

Met het oog op de gewenste intersubjectiviteit is elke stap door twee van de drie onderzoekers uitgevoerd, onafhankelijk van elkaar, waarna de één de analyse van de ander controleerde. Door de opdrachtgever is steekproefsgewijs gecontroleerd of de gegevens correct werden geanalyseerd. De verbatimverslagen zijn niet aan de respondenten voorgelegd; na analyse van de gegevens zijn wel de uitkomsten van de zeven stappen met de respondenten gecommuniceerd; hierop kwam geen commentaar.

\section{Resultaten}

\section{Algemene gegevens}

De uitkomsten van de algemene interviewvragen gaven inzicht in de opleiding die de respondenten gevolgd hebben, het jaar waarin zij afgestudeerd zijn als verpleegkundigen en de opgedane ervaring in een verpleeghuis. Ook werd gevraagd waarom de verpleegkundigen meedoen aan ethisch overleg.

Uitkomsten met betrekking tot algemene gegevens:

- De gevolgde opleidingen zijn zowel A-, B-, Z-opleidingen in de verpleging en de opleiding ziekenverzorging, als sociale opleidingen. Drie van de elf respondenten hebben de HBO-V gedaan.
- Gemiddeld waren de respondenten 15 jaar geleden gediplomeerd.

- De respondenten hebben gemiddeld 12 jaar werkervaring in de verpleeghuissector.

- Meer dan de helft van de respondenten (zes) geeft aan dat hun interesse in ethiek de motivatie is om te participeren in ethische overleg.

\section{Kennis, houding en vaardigheden}

$\mathrm{Er}$ is gevraagd naar de inhoud van de competenties (kennis, houding en vaardigheden) die nodig zijn om deel te kunnen nemen aan het ethisch overleg. Elk punt is een kernlabel uit de analyse. We geven de labels weer die meer dan één keer genoemd zijn.

Uitkomsten met betrekking tot kennis:

- Het belang van inzicht in de organisatie wordt het vaakst genoemd (7).

- Een meerderheid van de respondenten (6) vindt kennis van ethiek belangrijk voor deelname aan ethisch overleg. Waarden, normen en kennis van levensbeschouwing worden genoemd.

- Net minder dan de helft van de respondenten (5) geeft aan dat het belangrijk is kennis te hebben van wet- en regelgeving; een klein aantal respondenten (4) zegt kennistekort te ervaren op dit gebied.

Uitkomsten met betrekking tot houding:

- Een kleine minderheid van de respondenten (5) noemt het empathisch vermogen. Het duidt op het inleven in de besproken situaties en gesprekspartners.

- Het hebben van een professionele beroepshouding wordt door een klein aantal respondenten genoemd (3).

- Enkele respondenten vinden het respecteren van andere opvattingen belangrijk (3), evenals het openstaan hiervoor (2).

- Integriteit wordt door een aantal respondenten genoemd (3). 
- Een minderheid van de respondenten (3) noemt betrokkenheid bij de werkvloer. Aangezien het leidinggevenden zijn die dit antwoord geven, is dit apart opgenomen en niet samengevoegd met empathisch vermogen.

Uitkomsten met betrekking tot vaardigheden:

- Iets minder dan de helft van de respondenten (5) vindt luisteren een belangrijke vaardigheid.

- Verder wordt door respondenten (4) het afstand nemen als een professionele vaardigheid gezien. Relativeren wordt door een klein aantal genoemd (2).

- Argumenteren vinden 4 respondenten een belangrijke vaardigheid.

- Onder het item analyseren wordt door enkele respondenten (3) 'vragen stellen', 'helikopterview', en 'kunnen afwegen' genoemd.

\section{Onderwerpen}

De interviews gaven een goede indruk van de onderwerpen die besproken worden tijdens het ethisch overleg en/of in een ethische commissie. Het zijn sectorspecifieke onderwerpen waarvoor deelnemers aan ethisch overleg scholing nodig hebben. De volgende punten werden meer dan één keer genoemd:

- Dilemma's rond sterven en dood: alle respondenten (11).

- Dilemma's rond vocht- en voedingsbeleid: meer dan de helft van de respondenten (6).

- Pijnbestrijding: minder dan de helft van de respondenten (4).

- Beperkingen in de zorg die door de organisatie worden opgelegd of worden veroorzaakt (4).

- Aspecten van levensvisie en zingeving: enkele respondenten (2).

\section{Opgedane kennis, ervaren kennistekort en knelpunten}

Ook werd gevraagd waar verpleegkundigen hun kennis voor het kunnen deelnemen aan ethisch overleg opdeden en naar eventueel ervaren kennistekort, zowel in een ethische commissie als tijdens ethisch overleg. Ook de knelpunten in een ethisch overleg zijn op een rij gezet.

- Wat betreft de opgedane kennis was de uitkomst:

- Werkervaring wordt door de meeste respondenten (10) genoemd als een bron van kennis.

- Veel respondenten geven aan dat zij kennis hebben opgedaan in de opleidingen (7).

Wat betreft een eventueel kennistekort worden genoemd:

- Minder dan de helft van de respondenten (4) ervaart een kennistekort in weten regelgeving.

- Het vertalen van ethiek naar de werkvloer is voor een klein aantal respondenten een knelpunt (3).

- Kennistekort met betrekking tot begeleiding van teamleden en bewoners bij moeilijke onderwerpen wordt door enkele respondenten ervaren (2).

Ervaren knelpunten in houding en vaardigheden:

- Gevoel van tijdgebrek voor overleg wordt door enkele respondenten genoemd (3).

- Het niet kunnen vertalen van beleid en besluitvorming naar de werkvloer wordt door enkele respondenten genoemd (2).

- Enkele respondenten (2) missen een professionele attitude bij gevoelige onderwerpen. 


\section{Ethiek in de opleiding}

De respondenten werd gevraagd wat zij met betrekking tot ethiek verwachten van de opleiding tot verpleegkundige, onderverdeeld in kennis, houding, vaardigheden. Uitkomst:

- De helft van de respondenten (5) gaf aan dat het ethiekonderwijs op de opleiding verpleegkunde praktischer zou moeten zijn: meer casuïstiek c.q. ethische dilemma's om mee te oefenen, casuïstiek met betrekking tot terminale zorg, en casuïstiek die wordt ingebracht door ervaringsdeskundigen, niet alleen door docenten. Het meelopen in ethische commissie tijdens stages werd genoemd (2).

- Enkele respondenten vonden het belangrijk dat verpleegkundigen een eigen visie ontwikkelen, in samenhang met hun levensovertuiging en zelfinzicht (3).

- Vaardigheden die in een opleiding tot verpleegkundige geleerd moeten worden zijn: communicatie met familie en collega's, een casus van meerdere kanten be- lichten, doorvragen, kritisch zijn, en proactief opstellen in de organisatie (2).

\section{Conclusie}

De vraag was: welke competenties zeggen verpleegkundigen nodig te hebben om te kunnen participeren in ethisch overleg of in ethische commissies in verpleeghuizen? Op basis van de interviews is deze vraag beantwoord en zijn de uitkomsten weergegeven overeenkomstig een competentieprofiel dat ook in voorgaande onderzoeken is gebruikt. Daarin wordt gedetailleerd weergegeven welke kennis, houding en vaardigheden verpleegkundigen nodig hebben om te participeren in ethisch overleg (c.q. ethische commissies) in de verpleeghuiszorg. Daarmee kan tijdens de opleiding gerichter gewerkt worden aan de vorming van verpleegkundige competenties op het gebied van ethisch overleg. Daartoe zijn de uitkomsten van het onderzoek beschreven als onderstaande beroepscompetentie (zie Box 2). Hierbij werd het format aangehouden uit

Box 2. Verpleegkundig competentieprofiel.

Bij deelname van verpleegkundigen aan ethisch overleg in verpleeghuizen

gaat het om

- het kennen van wet- en regelgeving

- kennis hebben van ethiek, waaronder levensbeschouwing, normen en waarden, methodieken en ethisch redeneren

- inzicht hebben in de organisatie

- inzicht hebben in werk en beroep door (werk)ervaring.

- een open en respectvolle houding, zoals empathisch vermogen, professionele attitude en betrokkenheid

- kritisch kijken naar situaties en collegae, blijkend uit onder andere signaleren en helikopterview

- het vormen van een eigen visie.

- het toepassen van schriftelijke en mondelinge uitdrukkingvaardigheden

- het hebben van professionele vaardigheden zoals afstand nemen en relativeren

- het kunnen onderbouwen van eigen standpunten

- het in staat zijn om een ethisch probleem te analyseren

- het toepassen van omgangsvaardigheden.

zodat

verpleegkundigen, werkzaam in verpleeghuizen, competent participeren in ethische commissies en/of ethisch overleg. 
het boek van Pool et al. 'Met het oog op de toekomst'. ${ }^{6}$

\section{Discussie}

Uit wetenschappelijk oogpunt is dit praktijkonderzoek, waarin gedetailleerde informatie werd verzameld over de competenties die verpleegkundigen in verpleeghuizen nodig hebben om te kunnen participeren in ethische commissies of in andere gestructureerde vormen van ethisch overleg, slechts een begin. Het doel van deze verkenning was met de verkregen informatie bij te dragen aan het verpleegkundig onderwijs en aan het functioneren van verpleegkundigen op het terrein van ethiek in de praktijk. De competenties die verpleegkundigen nodig hebben om deel te nemen aan ethisch overleg zijn beschreven met aanbevelingen ter verbetering van het ethiekonderwijs aan (toekomstige) verpleegkundigen.

Uit de literatuur komt naar voren dat er zowel zorggerelateerde als organisatiegerelateerde dilemma's spelen in verpleeghuizen. In dit artikel zijn met name zorggerelateerde onderwerpen naar voren gekomen. Het is een open vraag of dit te maken heeft met de functie die de respondent in de organisatie inneemt: worden ethische onderwerpen door professionals op de werkvloer anders in een overleg ingebracht dan door leidinggevenden?

Opvallend was dat slechts twee van de benaderde verpleeghuizen een ethische commissie hebben. Zowel verpleegkundigen in de verpleeghuiszorg als de leiding van verpleeghuizen dienen zich dan ook af te vragen wat er in die sector gebeurt met ethische onderwerpen en wie daarover overleg voeren. Voor de competentie van verpleegkundigen maakt het mogelijk iets uit of dit overleg plaatsvindt in ethische commissies of in andere overlegvormen.

Gezien het aantal verpleeghuizen in ons land is elf respondenten niet veel. Het is de vraag of deze resultaten een afspiegeling zijn van de gehele verpleeghuiszorg. Door de willekeurige selectie van respondenten en de overeenstemming met cijfers over de verpleeghuissector, is er niet direct aanleiding anders te veronderstellen, maar de kans op toevallige afwijkingen is aanwezig.

Zowel in de onderzoeken die gedaan zijn binnen het algemene ziekenhuis, de thuiszorg, de geestelijke gezondheidszorg, de verstandelijk gehandicaptenzorg, als ook in deze verkenning, is aan verpleegkundigen gevraagd wat zij denken nodig te hebben om te kunnen participeren in een ethische commissie of te kunnen deelnemen aan ethisch overleg. Daar in alle sectoren een dergelijke verkenning heeft plaatsgevonden, verdient het aanbeveling de uitkomsten zo mogelijk te aggregeren en te toetsen onder verpleegkundigen. Ook is vervolgonderzoek nodig naar de vraag welke competenties verpleegkundigen nodig hebben volgens andere disciplines die participeren in ethisch overleg.

Tot slot kan ook de aansluiting gemaakt worden met het bredere belang van ethiekonderwijs aan andere gezondheidszorgprofessionals in de verpleeghuissector. In dit onderzoek werd gevraagd naar de visie van verpleegkundigen over verpleegkundige competenties. De bevindingen lijken op het eerste gezicht echter generiek van aard: kennis van wet- en regelgeving bijvoorbeeld dienen alle zorgverleners te hebben als zij deelnemen aan ethisch overleg. Ethiekonderwijs aan bijvoorbeeld verpleeghuisartsen zou daarmee gediend kunnen zijn. Om dat te bevestigen is een onderzoek onder andere gezondheidszorgprofessionals nodig.

\section{Aanbevelingen}

Volgens deze studie meent het merendeel van de respondenten dat ze met betrekking tot kennis, houding en vaardigheden 
voldoende onderwijs hebben genoten, misschien met uitzondering van kennis van wet- en regelgeving. Het ontbreekt hen echter aan ervaring. Zij kunnen wel participeren in ethisch overleg, maar niet als eindverantwoordelijke. Om hen te trainen in het participeren suggereert deze verkenning:

- in de opleiding meer casuïstiek aan te bieden, niet alleen in een rollenspel met studenten en docenten, maar ook met leden van ethische commissies die doceren vanuit hun eigen professie. Hierbij valt te denken aan medici, psychosociale zorgverleners en geestelijke verzorgers.

- in de stage een opdracht mee te geven om te observeren bij ethisch overleg of ethische commissie. Wanneer er geen ethische commissie is, laat de student dan een overleg over een ethisch dilemma organiseren waarbij meerdere disciplines aanwezig zijn. De student kan op deze manier oefenen.

- tijdens de opleiding aandacht te schenken aan relevante wet- en regelgeving, en welke bronnen men daarvoor kan raadplegen. Ook aandacht voor vragen rond dood en sterven c.q. vocht en voeding moet onderdeel zijn van het onderwijs.

\section{Literatuur}

1. Struijs A, Vathorst S van de. Morele dilemma's van verpleegkundigen en verzorgenden. Den Haag: Signalement Centrum voor Ethiek en Gezondheid; 2009. [Moral dilemmas for nurses and caregivers. The Hague: Centre for Ethics and Health, 2009].

2. Fazal A. Ethiek en gezondheidsrecht in het onderwijs. Een onderzoek naar het onderwijs van ethiek en gezondheidsrecht in de initiële artsopleiding en de voltijd HBO verpleegkunde opleiding. Scriptie Universiteit Twente: Faculteit der Bestuurskunde; 2001. [Ethics and health law in education. A study of ethics and health law during undergraduate medical education and fulltime higher vocational training in nursing. Master's thesis Twente University: Faculty of Management; 2001].
3. Munk MS. Ethiek in zorgopleidingen en zorginstellingen, achtergrondstudierapport in het kader van het Centrum voor Ethiek en Gezondheid. Zoetermeer; 2005. [Ethics in health professional education and health care institutions, report of a background study from the Centre for Ethics and Health. Zoetermeer; 2005].

4. Molewijk B, Widdershoven G. Moreel beraad: Methodisch omgaan met dagelijkse morele vragen. in Beaufort I de, et al. (red.). De kwestie. Praktijkboek ethiek voor de gezondheidszorg, Lemma, 2008, 81-91. [Moral consultations: a systematic approach to moral issues in day to day practice. In: Beaufort I de, et al. (eds). The Issue. Textbook on the Practice of Ethics in Health Care. Lemma, 2008, 81-91].

5. Leistra E, Liefhebber S et al. (red.). Beroepsprofiel van de verpleegkundige. Maarssen: Elsevier/Utrecht: LEVV; 1999. [The Nurse's Professional Profile. Maarssen: Elsevier/Utrecht. LEVV, 1999].

6. Pool A, Pool-Tromp C et al. (red.). Met het oog op de toekomst. Beroepscompetenties van Hbo-verpleegkundigen. Utrecht; 2001. [With a view to the future. Professional competencies of graduates from higher vocational education programmes in nursing. Utrecht; 2001].

7. Cusveller BS, Heuvel AE van den, Broek E van den, Maanen G van. Competenties van verpleegkundigen in ethische commissies. Verpleegkunde 2005; 20, nr. 1, 8-17. [Competencies of nurses on ethics boards. Nursing 2005; 20, nr 1, 8-17].

8. Kempkes-van den Bor N, Spek-Tronchet R, Twigt J, Cusveller BS. Competenties van psychiatrische verpleegkundigen in ethische commissies. Psychiatrie en Verpleging 2007; 83, nr. 4, 307-316. [Competencies of psychiatric nurses on ethics boards. Psychiatry and Nursing 2007;83, nr 4, 307-316].

9. Cusveller BS, Gaans T van, Jong $\mathbf{M}$ de. Thuis in ethiek. Wat heeft een verpleegkundige nodig voor ethisch overleg. Tijdschrift van de Landelijke Vereniging voor Wijkverpleegkundigen 2008; 8, nr. 1, 26-29. [At home in ethics. What do nurses need to take part in consultations on ethics. Journal of the National Association of District Nurses 2008; 8, nr. 1, 26-29].

10. Naaktgeboren P, Paul AH, Zaaijer-Voorhoeve ACA, Cusveller BS. Verpleegkundige deelname aan ethische commissies binnen de verstandelijke gehandicaptenzorg: de ontwikkeling van een competentieprofiel, Nederlands Tijdschrift voor de Zorg aan mensen met een verstandelijke beperking 2009; 35, nr. 4, 242-249. [Participation of nurses in ethics boards in institutions for the mentally disabled: development of a competency framework. Dutch Journal of Care for the Mentally Disabled 2009; 35, nr 4, 242-249]. 
11. Dartel JN van, Jacobs M, Jeurissen RJM. Ethiek bedrijven in de zorg. Een zaak van het management. Assen; 2002. [Practicing ethics in health care. A matter of management. Assen; 2002].

12. Thiel van $G$, Hove $M$ van den. Als mensen aandacht tekort komen, smaakt het kopje thee ook niet. Ethische vragen in de care-sector. Centrum voor Bio-Ethiek en gezondheidsrecht, Universiteit Utrecht; 1999. [Without sufficient attention, people don't enjoy their cup of tea. Ethical Issues in Health Care. Centre for Bio-ethics and Health Law, Utrecht University; 1999].

13. Molewijk, B., G. Widdershoven, Moreel beraad en goede zorg voor ouderen veronderstellen en versterken elkaar. Tijdschrift voor Geneeskunde, 2006; 62, nr. 23, 1693-1701. [Ethics consultations and good care for the elderly are mutually dependent and reinforcing. Journal of Medicine, 2006;62(23):1693-1701].

14. Molewijk B, Dam S van der, Bruijn A, Kardol T, Widdershoven G. Moreel beraad in de verpleeghuiszorg: methodisch spreken over goede zorg, Tijdschrift voor verpleeghuisgeneeskunde 2009, vol. 34, nr. 3, 103-106. [Ethics consultations in nursing home care: a systematic approach to good care. Journal of Nursing Home Care 2009;34(3):103-106].

15. http://www.nu91-leden.nl/faq.asp?fid=70 (geraadpleegd 10 december). Accessed 10 December.

16. Cusveller B. Ethiek. In Hunink G. et al. (red.). De verpleegkundige als beroepsbeoefenaar. Utrecht: ThiemeMeulehoff; 2006. [The Nurse as Professional. Utrecht: ThiemeMeulehoff; 2006].
17. Cluitmans JJ, Dekkers MAF, Oeffelt T van. Aan de slag met competenties: competentiegericht leren in $\mathrm{HBO}$ en $\mathrm{MBO}$. Nuenen: Onderwijsadviesbureau Dekkers; 2002. [Working with competencies: competency-based learning in higher and intermediate vocational education. Nuenen: Dekkers, Educational Consultants; 2002].

18. Baarda DB, Goede MPP de, Teunissen J. Basisboek kwalitatief onderzoek. 2e geheel herziene druk. Groningen/Houten; 2005. [A primer on qualitative research. 2 nd revised edition. Groningen/Houten; 2005].

\section{De auteurs:}

Bart Cusveller is lector Verpleegkundige Beroepsethiek aan de Academie Gezondheidszorg van de Christelijke Hogeschool Ede.

Hermen Huijser is als verpleegkundige werkzaam bij Thuiszorg Rotterdam.

Daniëlle Klinkhamer-Hazeleger is als verpleegkundige werkzaam in verpleeghuis De Meent te Veenendaal.

Jacqueline Zwart-van Dommelen, is als verpleegkundige werkzaam in het Diaconessenhuis te Utrecht.

\section{Correspondentieadres:}

Dr. B.S. Cusveller, Academie Gezondheidszorg, Christelijke Hogeschool Ede, postbus 80, 6710 BB Ede.Tel.: 0318-696300; e-mail:bcusveller@che.nl

Belangenconflict: geen gemeld

Financiële ondersteuning: geen gemeld

\section{Summary}

Introduction: Nurses are confronted with ethical issues in all settings, including nursing homes. According to the professional nursing competency profile, nurses should be able to participate in ethics committees. However, it is not clear what this competency entails or how it is taught. We conducted a study to investigate which competencies nurses should have in order to be able to participate in organised forms of ethical deliberations (whether in an ethics committee or otherwise) in nursing homes.

Method: We interviewed eleven nurses from randomly selected nursing homes who participated in formal discussions on ethical issues in their institution. The interview questions related to professional competencies (i.e. knowledge, attitude and skills) and to ethics-related formal deliberations, issues and education.

Results: The results are presented as a nursing competency profile with recommendations for nursing education. Some issues were considered to be of particular importance: knowledge about the institution, legal issues and regulations, an empathetic and respectful attitude and listening and reasoning skills. All respondents had experienced dilemmas around death and dying, particularly in relation to feeding and nutrition.

Conclusion: Nurses with some work experience are able to participate in deliberations around ethical issues. However, they experience deficiencies in knowledge about legislation and regulations. Ethics education during nursing training should be more practical and based on cases. The results seem to be generic and have relevance to other health care professionals as well. (Cusveller B, Huijser H, Klinkhamer-Hazeleger D, Zwart-van Dommelen J. Competencies of nurses for ethical consultations in nursing homes. Netherlands Journal of Medical Education 2011;30(1-2):11-21) 